\title{
Quantitative analysis of lycorine in Galanthus alpinus Sosn. var. alpinus by HPLC-DAD
}

\author{
Ceren Emir*, Nehir Ünver Somer \\ Department of Pharmacognosy, Faculty of Pharmacy, Ege University, Bornova, İzmir, Turkey
}

Cite this article as: Emir C, Ünver Somer N. Quantitative analysis of lycorine in Galanthus alpinus Sosn. var. alpinus by HPLCDAD. Istanbul J Pharm 48 (2): 32-37.

\begin{abstract}
In this study, a reversed-phase, high pressure liquid chromatography (RP-HPLC) method was applied in the quantitative analysis of lycorine in the aerial parts and bulbs of Galanthus alpinus Sosn. var. alpinus collected from Rize during the flowering and fruiting seasons. A simple method to extract lycorine from the plant specimens was performed, using pre-packed columns with diatomaceous earth (Extrelut ${ }^{\circledR}$ ). The chromatographic separation was achieved employing an isocratic system with a mobile phase including trifluoroacetic acid-water-acetonitrile (0.01:95:5) measured at a flow rate of $1 \mathrm{~mL} / \mathrm{min}$ using a diode array detector (DAD). The lycorine content in the bulbs during the flowering and fruiting seasons was detected as 0.01576 and $0.02351 \%$, respectively. Also, validation studies showed that the method was specific, accurate and precise.
\end{abstract}

Keywords: Galanthus alpinus Sosn. var. alpinus, Amaryllidaceae, lycorine, HPLC-DAD

\section{INTRODUCTION}

Galanthus alpinus var. alpinus is an Amaryllidaceous plant distributed throughout the Caucasus/Transcaucasus region (Russia, Georgia, Armenia) and North-East Turkey. It is only found in the province of Rize in our country (Bishop et al. 2006). The Galanthus species, belonging to the Amaryllidaceae family, include diverse types of alkaloids with a wide range of biological and pharmacological activities (Unver 2007; Berkov et al. 2012). Among these alkaloids, galanthamine is a long-acting, reversible, selective and competitive acetylcholinesterase inhibitor used clinically for the treatment of mild to moderate Alzheimer's disease (Heinrich and Teoh 2004). Another important metabolite - lycorine (the main phenanthridine Amaryllidaceae alkaloid) - has been proven to possess several biological activities such as antiinflammatory (Saltan Çitoğlu et al. 2012), antiviral (Li et al. 2005; Oluyemisi et al. 2015), antimalarial (Şener et al. 2003), antifungal (Shen et al. 2014; Locarek et al. 2015), antiparasitic (Giordani et al. 2011; Giordani et al. 2012) and hepatoprotective (Ilavenil et al. 2012) effects. In particular, lycorine showed significant cytotoxic activity over different cancer cell lines due to its chemical structure (Nair and van Staden 2014; Doskočil et al. 2015; Nair et al. 2016) as shown in Figure 1.

Recently, herbal medicines have been used much more globally. Consequently their quality-control processes have been called into question in therapeutic utilization. With this in mind, in this study, plant extracts obtained from G. alpinus var. alpinus were investigated for their content of galanthamine and lycorine.

\section{MATERIALS AND METHODS}

\section{Plant Material}

Specimens of G. alpinus var. alpinus were collected from Çamlıhemşin, Rize on March 29, 2012 and April 5, 2013 during the flowering and fruiting periods. The plants were identified by Prof. Dr. M. Ali ONUR and voucher samples of G. alpinus var. alpinus (No:1513, 1526) have been deposited in the Herbarium of the Department of Pharmacognosy, Faculty of Pharmacy, Ege University. 


\section{Chemicals and Solvents}

Lycorine was isolated from G. alpinus var. alpinus and verified by multifarious spectroscopic methods $\left({ }^{1} \mathrm{H}\right.$ and ${ }^{13} \mathrm{C}$ NMR, MS). HPLC grade acetonitrile (LabScan Analytical Sciences, LC 1005), and chromatographic grade double-distilled water, TFA (trifluoroacetic acid) (Merck, 108178) were used for the HPLC analysis of analytes and standards.

\section{Sample Preparation}

The dried and powdered aerial parts and bulbs of the plant (200 mg) were macerated with $5 \mathrm{~mL}$ of $2 \%$ hydrochloric acid for $5 \mathrm{~h}$ in an ultrasonic bath at $40^{\circ} \mathrm{C}$, the extract was made alkaline with $1 \mathrm{~mL}$ of $26 \%$ ammonium hydroxide and the volume was adjusted to $10 \mathrm{~mL}$ in a volumetric flask with distilled water. Following centrifugation at $5000 \mathrm{rpm}$ for $10 \mathrm{~min}$, aliquots of $3.0 \mathrm{~mL}$ were applied to the Extrelut ${ }^{\oplus}$ columns. After $10 \mathrm{~min}$, the alkaloids were eluted with $(5 \mathrm{~mL} \times 3)$ chloroform. The organic solvent was distilled under pressure to afford the alkaloidal extract. The extract was dissolved in $1 \mathrm{~mL} 0.1 \%$ TFA, passed through a $0.45-\mu \mathrm{m}$ filter (Grace Davison, USA), and $20 \mu \mathrm{L}$ of the filtrate was injected into the HPLC column for analysis.

\section{Chromatography}

The analysis of the samples and validation experiments were carried out using a liquid chromatografic system (Agilent 1100 series) equipped with a quaternary pump, a vacuum degasser, a thermostatted column compartment, a manual injector with $20 \mu \mathrm{L}$ loop (Rheodyne 7725i), a diode array detector (DAD) (Agilent 1200 series) and software Agilent ChemStation. The chromatographic resolution was performed with an isocratic mobile phase including TFA-water-acetonitrile (0.01:95:5) on a Hichrom C18 column (5 $\mu \mathrm{m}$ particle size, $250 \mathrm{~mm}, 4.6 \mathrm{~mm}$ ) at a flow rate of $1 \mathrm{~mL} / \mathrm{min}$ and $\lambda_{\max } 290 \mathrm{~nm}$ at $25^{\circ} \mathrm{C}$. The injection volume was $20 \mu \mathrm{L}$. The chromatographic run time was $45 \mathrm{~min}$. All the calculations regarding the quantitative determinations were carried out by an external standard method based on peak areas.

\section{Method Validation}

Assessment of linearity, accuracy and precision studies were carried out according to the $\mathrm{ICH}$ validation guidelines $(\mathrm{ICH}$ 2005).

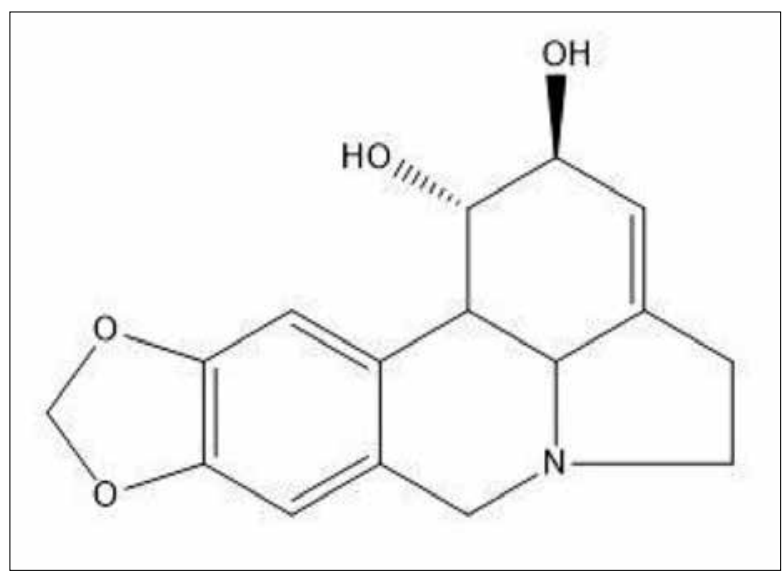

Figure 1. Chemical Structure of lycorine

\section{Linearity}

Standard stock solutions of lycorine were prepared by dissolving $2 \mathrm{mg}$ in $5 \mathrm{~mL} 0.1 \%$ TFA. Afterwards this solution was diluted with $0.1 \%$ TFA to attain solutions at 2.5, 5.0, 7.5, 10.0, 15.0 and $20.0 \mu \mathrm{g}$ $\mathrm{mL}^{-1} .20 \mu \mathrm{L}$ of standard solution was injected into the column in triplicate and then a calibration curve was constructed by plotting the peak areas of lycorine against its respective concentrations.

\section{Precision}

Intra-day and inter-day precisions were used to study the repeatability and reproducibility of the method. For the intra-day variability test, six different concentrations of standard lycorine were applied in triplicate on the same day while for the interday test, the standard lycorine was analysed by performing the same procedure on two different days.

\section{Limits of Detection (LOD) and Quantification (LOQ)}

Limit of detection and limit of quantification were determined by injecting the standard solution until the signal to noise ratio $(\mathrm{S} / \mathrm{N})$, was about 3 for LOD and 10 for LOQ. The LOD and LOQ were experimentally verified by ten injections of lycorine.

\section{Recovery}

Accuracy of the method was checked via recovery studies performed by a standard addition method. Mixed standard solutions with three different concentration levels were prepared and added to the plant sample and the mixtures were analyzed using the proposed method utilized in the quantitative determination of lycorine in the plant samples.

\section{Specificity}

Specificity is the ability to specifically measure the analyte in the presence of other components - typically including impurities, degradants, matrix etc. The specificity of the method was determined by the detection of lycorine in the presence of other constituents present in the extract. The selectivity of peaks of lycorine in the samples was evaluated by comparing their retention time and UV $\lambda_{\max }$ with the lycorine standard.

\section{RESULTS}

\section{Sample Analysis}

The results of quantitative determination of lycorine in the bulbs of $G$. alpinus var. alpinus are scheduled in Table 1. The chromatograms of the standard lycorine and plant extracts are shown in Figures 2-4. The identification of lycorine in plant specimens was achieved by comparison of the retention time and the UV spectrum of standard lycorine. The combination of the mobile phase was decided regarding maximum separation and selectivity. In accordance with this, the TFA-water-acetonitrile (0.01:95:5) mobile

Table 1. Lycorine content of G. alpinus var. alpinus

\begin{tabular}{lcc|}
$\begin{array}{l}\text { G. alpinus var. } \\
\text { alpinus (Season) }\end{array}$ & Specimen & $\begin{array}{c}\text { Content of } \\
\text { Lycorine }(\%)\end{array}$ \\
\hline Flowering & Bulbs & $0.01576 \pm 0.001686$ \\
Fruiting & Aerial Parts & ND \\
& Bulbs & $0.02351 \pm 0.0003182$ \\
& Aerial Parts & ND \\
\hline ND: Not Detected & & \\
\hline
\end{tabular}


Istanbul J Pharm 48 (2): 32-37

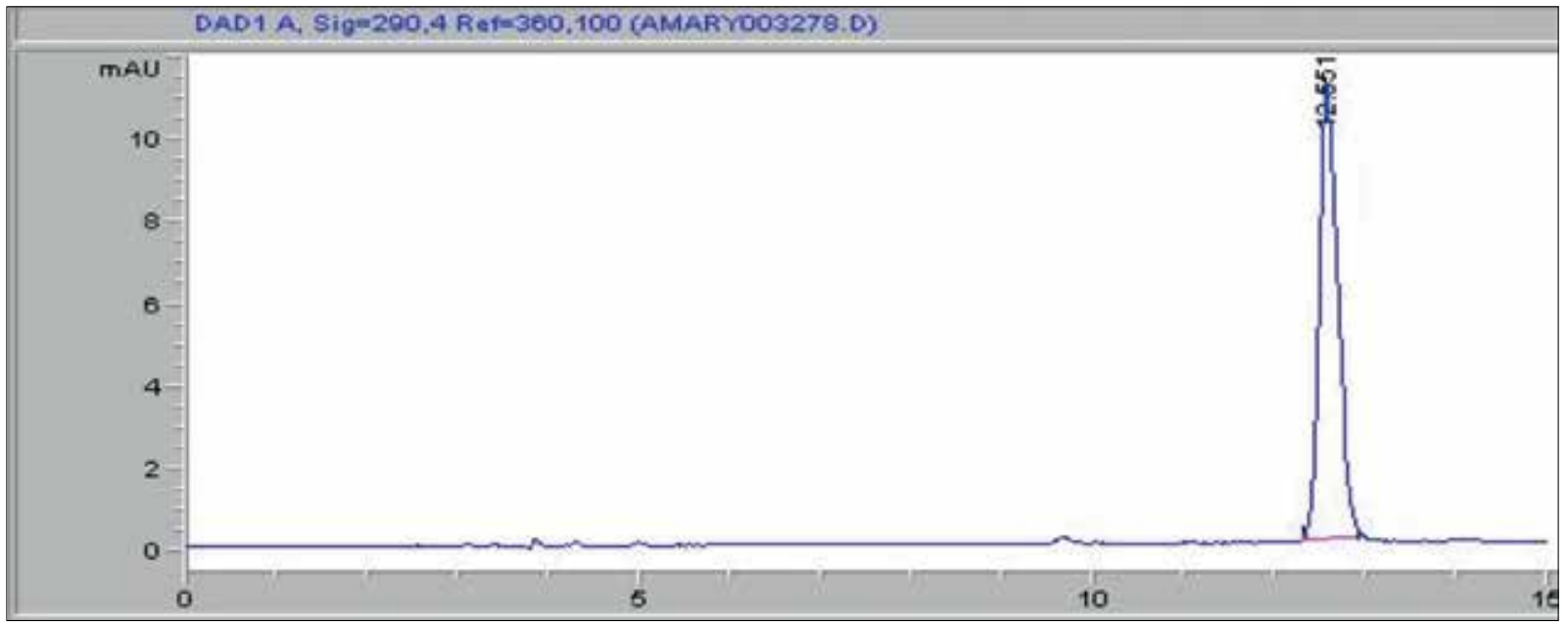

Figure 2. HPLC chromatogram of standard lycorine $(\mathrm{Rt}=12.551)$

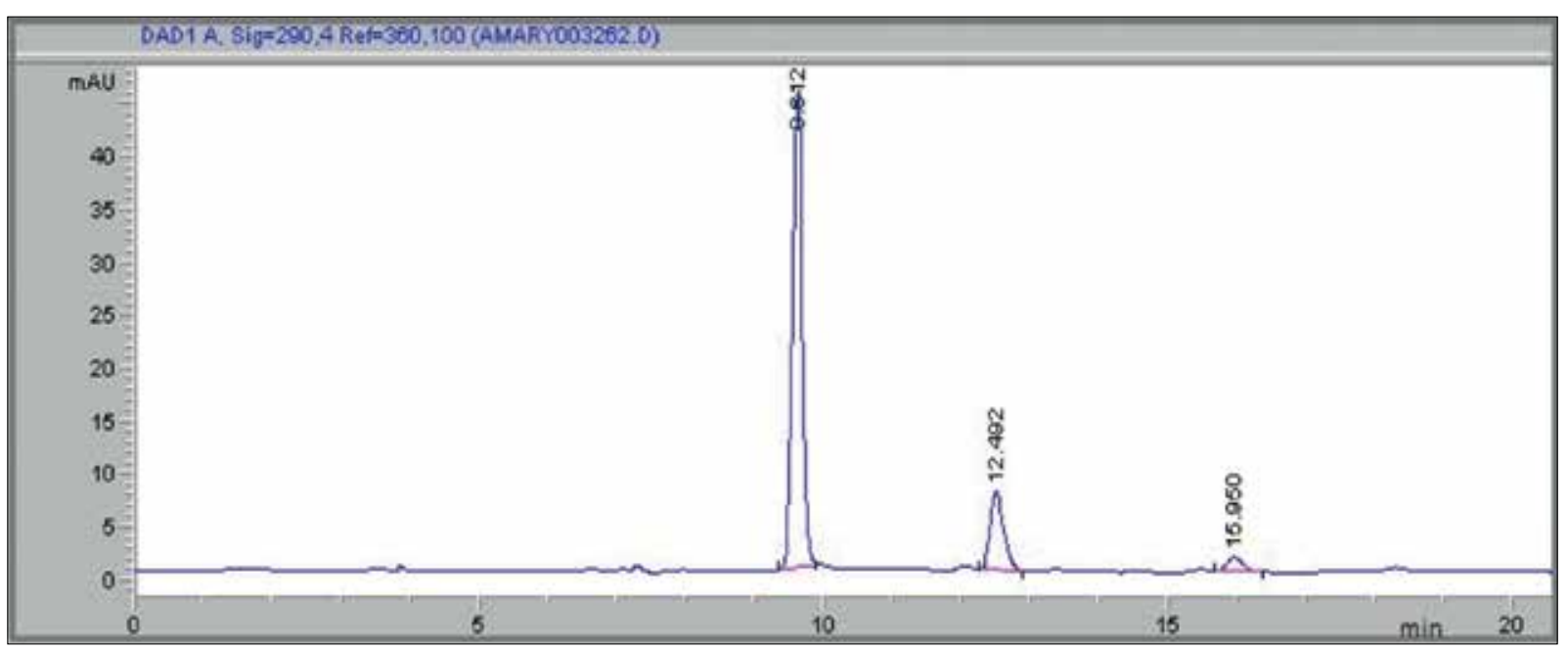

Figure 3. HPLC chromatogram of an alkaloidal extract from $G$. alpinus var. alpinus (Bulbs; flowering period) $(\mathrm{Rt}=12.492)$

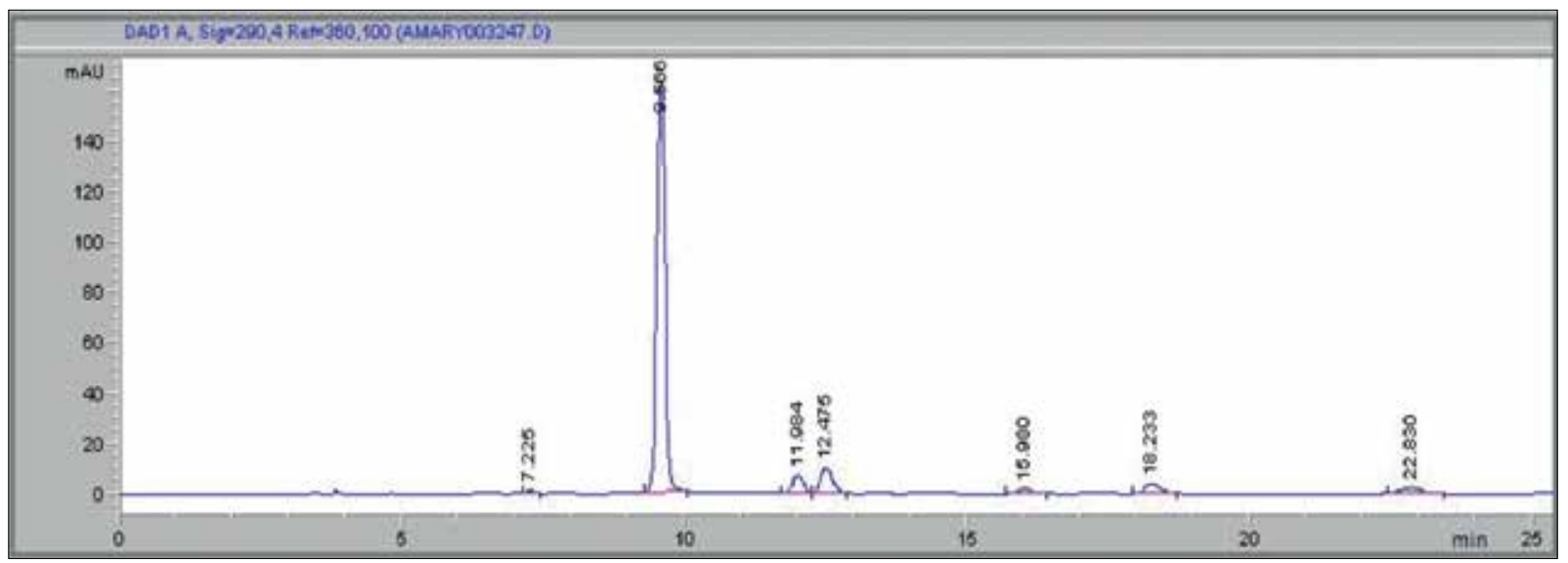

Figure 4. HPLC chromatogram of an alkaloidal extract from $G$. alpinus var. alpinus (Bulbs ; fruiting period) ( $\mathrm{Rt}=12.475)$

phase system was used. Under the described chromatographic conditions, the quantitative analysis of lycorine was performed in triplicate using the external standard method based on peak areas. As a result, the lycorine content was detected as 0.01576 and $\% 0.02351 \%$ in the bulbs of plant specimens collected during flowering season and fruiting season, respectively. Lycorine was not detected in quantitative amounts in the aerial parts of this Galanthus species. Also, specimens of $G$. alpinus var. alpinus were 


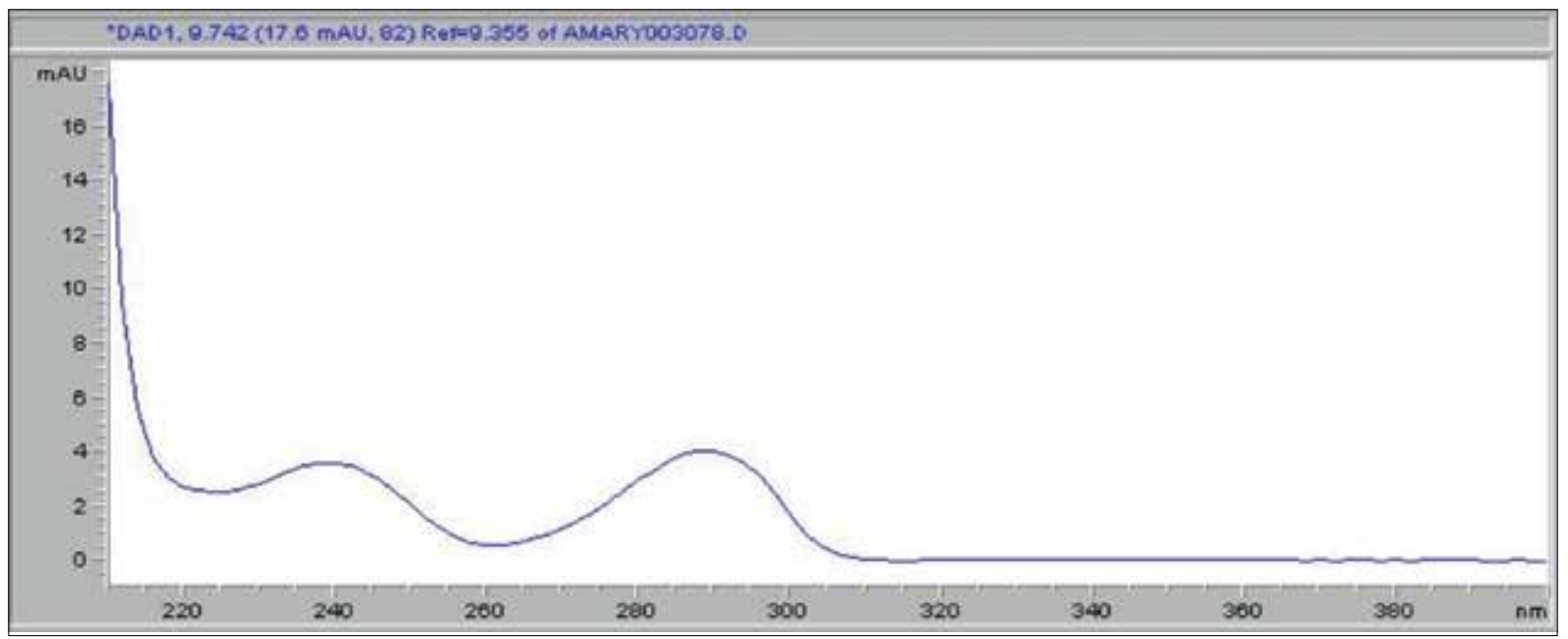

Figure 5. UV Spectrum of standart lycorine

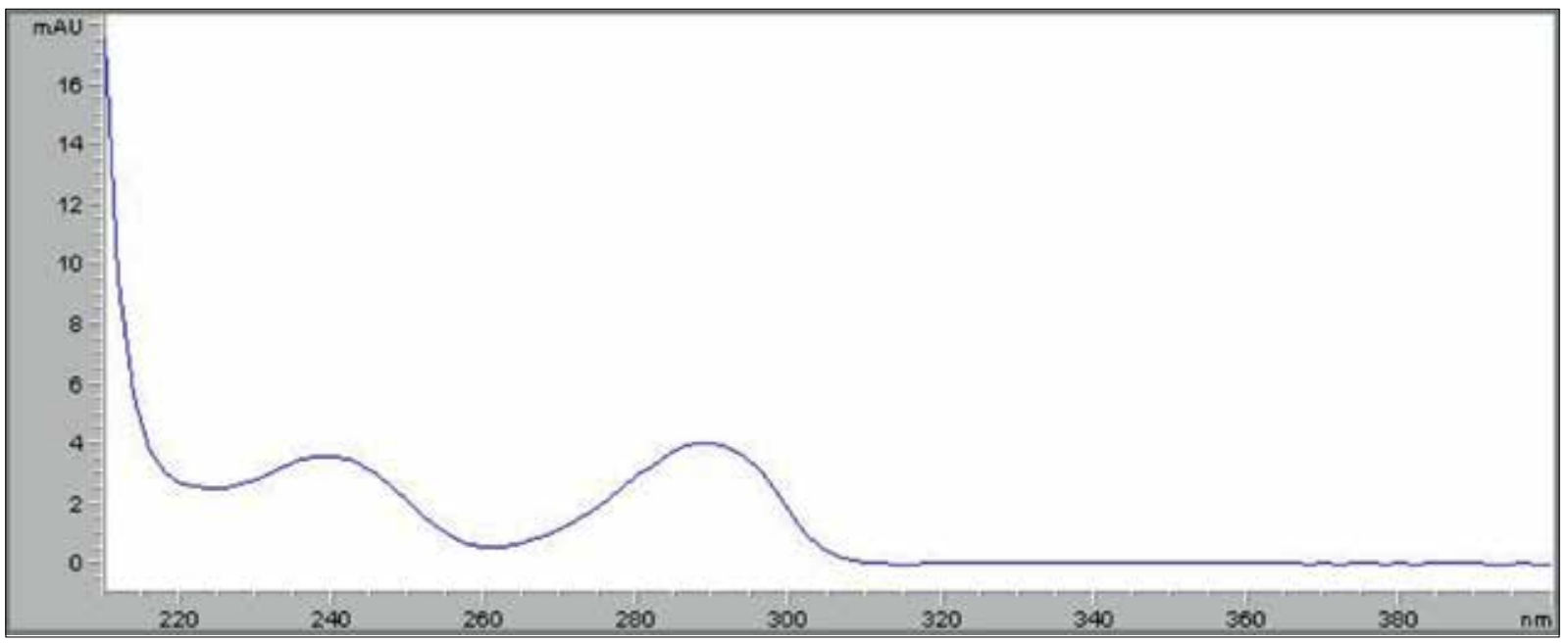

Figure 6. UV Spectrum of lycorine in extract of bulbs (flowering period)

Table 2. Intra-day and inter-day precision of lycorine for G. alpinus var. alpinus

\begin{tabular}{|lccc|} 
Compound & $\begin{array}{c}\text { Amount } \\
(\mu \mathrm{g} / \mathrm{mL})\end{array}$ & $\begin{array}{c}\text { Intra-day } \\
\text { Precision } \\
(\text { RSD, \%) }\end{array}$ & $\begin{array}{c}\text { Inter-day } \\
\text { Precision } \\
\text { (RSD, \%) }\end{array}$ \\
\hline Lycorine & 2.5 & 0.958 & 0.869 \\
& 5 & 1.252 & 1.276 \\
& 7.5 & 0.771 & 1.213 \\
& 10 & 0.870 & 0.743 \\
& 15 & 0.984 & 0.214 \\
& 20 & 0.896 & 1.001 \\
\hline ND: Not Detected & & & \\
\hline
\end{tabular}

investigated for their galanthamine content, but it was detected neither in the aerial parts nor in the bulbs of this plant.

\section{Method Validation}

\section{Linearity}

The regression equation for lycorine was found as $y=10.73592 x-2.67864$. Perfect linearity was acquired $\left(r^{2}=0.99965\right)$ performing a good correlation between the alkaloid concentration and its peak area.

\section{Precision}

The results of the precision analysis of lycorine are summarized in Table 2. RSD values were found to be less than $1.5 \%$ which indicated plausible repeatability for this method.

\section{Limits of Detection (LOD) and Quantification (LOQ)}

The LOD (signal /noise ratio of 3:1) was calculated as $0.037 \mu \mathrm{g}$ $\mathrm{mL}^{-1}$ and the LOQ (signal/noise ratio of 10:1) was determined as $0.125 \mu \mathrm{g} \mathrm{mL}^{-1}$. At the LOD and LOQ levels RSD \% was determined to be 9.96 for lycorine.

\section{Recovery}

The mean extraction recovery of lycorine was found within the range of $94.289-98.533 \%$. The results of the experiments are given in Table 3.

\section{Specificity}

Peak purity of lycorine was evaluated by the acquisition of UV spectra with the DAD detector. The spectra of the analyzed compound is shown in Figures 5-7. 


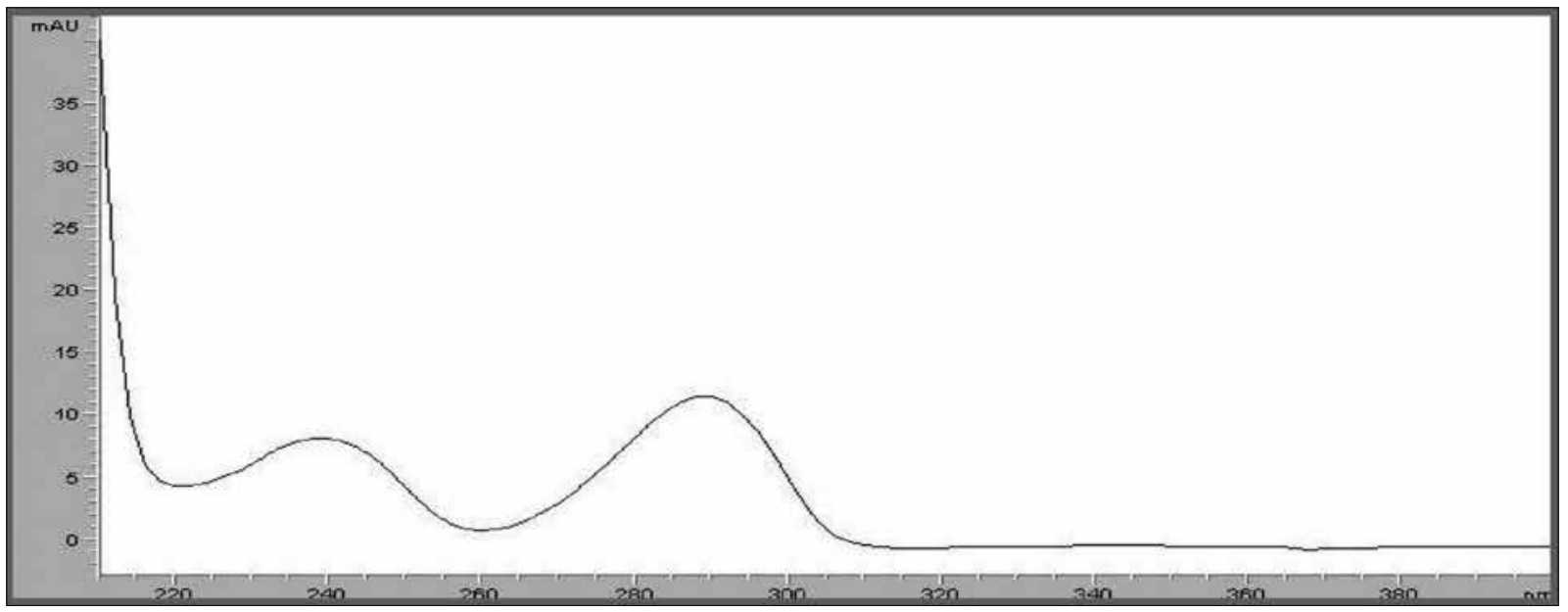

Figure 7. UV Spectrum of lycorine in extract of bulbs (fruiting period)

Table 3. Statistical data for recovery studies of lycorine

\begin{tabular}{|lccccc|} 
Compound & $\begin{array}{c}\text { Concentration } \\
\text { in Sample } \\
(\mathrm{mg} / \mathrm{mL})\end{array}$ & $\begin{array}{c}\text { Amount } \\
\text { Spiked } \\
(\mathrm{mg} / \mathrm{mL})\end{array}$ & $\begin{array}{c}\text { Mean Amount } \\
\text { Found in } \\
\text { Mixture }(\mathrm{mg} / \mathrm{mL})\end{array}$ & $\begin{array}{c}\text { Mean } \\
\text { Recovery } \\
(\%) \pm S D\end{array}$ & RSD (\%) \\
\hline Lycorine & 0.01 & 0.005 & 0.0074 & $98.533 \pm 0.14$ & 0.143 \\
& 0.01 & 0.01 & 0.0094 & $94.289 \pm 1.158$ & 1.228 \\
& 0.01 & 0.02 & 0.0144 & $96.257 \pm 0.439$ & 0.456 \\
\hline
\end{tabular}

\section{DISCUSSION}

Quantitative analysis of lycorine in the Galanthus species was accomplished using a chromatographic method with different separation selectivity and a high system efficiency. Additionally, simple and rapid sample preparation, small plant samples and basic composition of the mobile phase are counted among the other benefits of the method. The method was validated in accordance with linearity, precision, recovery and limits of detection and quantification. This simple, rapid and reliable HPLC method is suitable for the quantitative analysis of lycorine, which is a biologically important Amaryllidaceae alkaloid. Comparisons between the samples from the flowering and fruiting periods showed a higher lycorine content during the fruiting period of G. alpinus var. alpinus. . Moreover, significant differences in the content of this alkaloid have been observed in the aerial parts and bulbs. In previous studies, several Galanthus species were reported to contain only lycorine - not galanthamine -as in the results of this study. Finally, lycorine content was calculated to be higher in bulbs than aerial parts in accordance with relevant literature (Kaya et al. 2004; Sarıkaya et al. 2012; Unver Somer et al. 2013; Kaya et al. 2014; Emir et al. 2017). The fact that the diversity of these alkaloids, their distribution and amounts are different in species and populations, may be explained by infraspecific variations which are influenced by several factors such as polymorphisms in genotype as well as stage of maturity, soil composition and the different climate and drying conditions (Larsen et al. 2010). To the best of our knowledge, this is the first report on the quantification of lycorine in $G$. alpinus var. alpinus of Turkish origin.

\section{Acknowledgements}

The financial support of Ege University Research Fund (project number 2014/ECZ/038) was acknowledged.

Conflict of Interest: The authors have no conflict of interest to declare.

\section{REFERENCES}

- Berkov S, Codina C, Bastida J (2012). The genus Galanthus: A Source of bioactive compounds. In: Rao V (ed.) PhytochemicalsA Global Perspective of Their Role in Nutrition and Health. InTech, Rijeka, pp. 235-254. [CrossRef]

- Bishop M, Davis A, Grimshaw J (2006). Snowdrops. Griffin Press Publishing Ltd., Cheltenham: UK.

- Doskočil I, Hoštálková A, Šafratová M, Benešová N, Havlík J, Havelek R, Kuneš J, Královec K, Chlebek J, Cahlíková L (2015). Cytotoxic activities of Amaryllidaceae alkaloids against gastrointestinal cancer cells. Phytochem Lett 13:394-8. [CrossRef]

- Emir A, Emir C, Bozkurt B, Onur MA, Somer NU, Kaya Gl (2017). Application of HPLC-DAD for the quantification of Lycorine in Galanthus elwesii Hook. Brazilian J Pharm Sci 53(1):1-6. [CrossRef]

- Giordani RB, De Brum Vieira P, Weizenmann M, Rosemberg DB, Souza AP, Bonorino C, De Carli GA, Bogo MR, Zuanazzi JA, Tasca $T$ (2011). Lycorine induces cell death in the amitochondriate parasite, Trichomonas vaginalis, via an alternative non-apoptotic death pathway. Phytochemistry 72(7):645-50. [CrossRef]

- Giordani RB, Junior COR, de Andrade JP, Bastida J, Zuanazzi JAS, Tasca T, de Almeida MV (2012). Lycorine derivatives against Trichomonas vaginalis. Chem Biol Drug Des 80(1):129-33. [CrossRef]

- Heinrich M, Teoh HL (2004). Galanthamine from snowdrop - The development of a modern drug against Alzheimer's disease from local Caucasian knowledge. J Ethnopharmacol 92(2-3):147-62. [CrossRef] 
- $\quad$ ICH Guidelines Q2(R1) (2005). Validation of Analytical procedures: Text and Methodology. Geneva.

- $\quad$ llavenil S, Kaleeswaran B, Ravikumar S (2012). Protective effects of lycorine against carbon tetrachloride induced hepatotoxicity in Swiss albino mice. Fundam Clin Pharmacol 26:393-401. [CrossRef]

- Kaya G, Fillik A, Hışı Y, Ünver N (2004). High pressure liquid chromatographic analysis of lycorine in four Galanthus species growing in Turkey. Turkish J Pharm Sci 1(2):105-14.

- $\quad$ Kaya G, Çiçek D, Sarikaya B, Onur M, Somer NÜ (2014). Quantitative Determination of Lycorine and Galanthamine in Galanthus trojanus and G. cilicicus by HPLC-DAD. Nat Prod Commun 9(8):1157-1158.

- Larsen MM, Andersen A, Davis AP, Lledó MD, Jäger AK, Rønsted N (2010). Using a phylogenetic approach to selection of target plants in drug discovery of acetylcholinesterase inhibiting alkaloids in Amaryllidaceae tribe Galantheae. Biochem Syst Ecol. 38:1026-1034. [CrossRef]

- $\quad$ Li SY, Chen C, Zhang HQ, Guo HY, Wang H, Wang L, Zhang X, Hua S, Yu J, Xiao P, Li R, Tan X (2005). Identification of natural compounds with antiviral activities against SARS-associated coronavirus. Antiviral Res 67(1):18-23. [CrossRef]

- Locarek M, Novakova J, Kloucek P, Host'alkova A, Kokoska L, Gabrlova L, Safratova M, Opletal L, Cahlíkova L (2015). Antifungal and antibacterial activity of extracts and alkaloids of selected Amaryllidaceae species. Nat Prod Commun. 10(9):1537-40.
Nair JJ, van Staden J (2014). Cytotoxicity studies of Lycorine alkaloids of the Amaryllidaceae. Nat Prod Commun 9(8):1193-210.

- $\quad$ Nair JJ, van Staden J, Bastida J (2016). Apoptosis-Inducing Effects of Amaryllidaceae Alkaloids. Curr Med Chem 23:161-85. [CrossRef]

Oluyemisi OO, Oriabure AE, Adekunle AJ, Soup K, Ramsay T, Shyyaula S (2015). Bioassay-guided isolation of Poliovirus-inhibiting constituents from Zephyranthes candida. Pharm Bio/ 53(6):882-7. [CrossRef]

- Saltan Çitoğlu G, Bahadir Acikara O, Sever Yilmaz B, Özbek H (2012). Evaluation of analgesic, anti-inflammatory and hepatoprotective effects of lycorine from Sternbergia fisheriana (Herbert) Rupr. Fitoterapia 83(1):81-7. [CrossRef]

- Sarikaya BB, Somer NU, Onur MA (2012). Quantitative Determinations on Galanthus rizehensis. Turkish J Pharm Sci 9(1):61-6.

- $\quad$ Shen JW, Ruan Y, Ren W, Ma BJ, Wang XL, Zheng CF (2014). Lycorine: A potential broad-spectrum agent against crop pathogenic fungi. J Microbiol Biotechno/ 24(3):354-8. [CrossRef]

- S Sener B, Orhan I, Satayavivad J (2003). Antimalarial activity screening of some alkaloids and the plant extracts from Amaryllidaceae. Phytother Res 17(10):1220-3. [CrossRef]

- Unver N (2007). New skeletons and new concepts in Amaryllidaceae alkaloids. Phytochem Rev 6:125-35. [CrossRef]

- Unver Somer N, Cicek Polat D, Emir A, Onur M, Kaya G (2013). Quantitative analysis of lycorine in endemic Galanthus xvalentinei notho subsp. subplicatus by HPLC-DAD. Acta Chromatogr 25(2):331-338. [CrossRef] 